\title{
Meningkatkan Hasil Belajar Pendidikan Agama Islam Materi Q.S. Yunus/10: 40-41 Dan Q.S. Al-Maidah /5: 32 dengan Model Pembelajaran Discovery Learning pada Siswa Kelas XI
}

\author{
Rukiah Ali ${ }^{*}$ \\ ${ }^{1}$ SMK Negeri 5 Kota Ternate, Ternate, Indonesia
}

\section{A R T I C L E I N F O}

Article history:

Received May 16, 2021

Revised May 28, 2021

Accepted June 02, 2021

Available online August 25, 2021

Kata Kunci:

Pendidikan Agama Islan, Model Discovery Learning

Keywords:

Islamic Religious Education, Discovery Learning Model

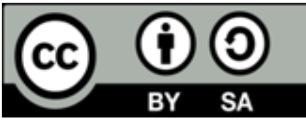

This is an open access article under the CC BY-SA license.

Copyright (@) 2021 by Author. Published by Universitas Pendidikan Ganesha.

\begin{abstract}
A B S T R A K
Rendahnya hasil pembelajaran pendidikan agama islam disebabkan karena kurangnya penggunaan model pembelajaran yang sesuai dengan materi pembelajaran. Sehingga tujuan dari penelitian ini yakni untuk mengetahui peningkatan hasil belajar Pendidikan Agama Islam melalui pelaksanaan model pembelajaran Discovery Learning pada siswa kelas XI SMK. Penelitian ini merupakan jenis penelitian tindakan kelas yang dilakukan sebanyak tiga putaran. Setiap putaran terdiri dari empat tahap yaitu: Rancangan, Pelaksanaan Kegiatan dan pengamatan, Observasi, dan Refleksi/Tindakan. Teknik pengumpulan data dilakukan dengan tekni observasi, tes dokumentasi dan wawancara. Adapun hasil penelitian menunjukkan bahwa terdapat peningkatan hasil belajar siswa pada setiap siklusnya, dimana pada siklus I nilai rata-rata siswa hanya 79 , dan meningkat pada siklus II menjadi 83. Sehingga dapat disimpulkan bahwa penggunaan model pembelajaran discovery learning secara signifikan dapat meningkatkan hasil belajar agama islam siswa kelas IX Sekolah menengah kejuruan.
\end{abstract}

\section{A B S T R A C T}

The low learning outcomes of Islamic religious education are caused by the lack of use of learning models that are in accordance with the learning material. So the purpose of this research is to find out the improvement of Islamic Religious Education learning outcomes through the implementation of the Discovery Learning learning model in class XI SMK students. This research is a type of classroom action research conducted in three rounds. Each round consists of four stages, namely: Design, Implementation of Activities and observations, Observation, and Reflection/Action. Data collection techniques were carried out by means of observation, documentation tests and interviews. The results showed that there was an increase in student learning outcomes in each cycle, where in the first cycle the average value of students was only 79, and increased in the second cycle to 83 . So it can be concluded that the use of discovery learning learning models can significantly improve religious learning outcomes. Islam students of class IX Vocational High School.

\section{PENDAHULUAN}

Pendidikan merupakan salah satu kegiatan yang dilaksanakan untuk mengembangkan kualitas umber daya manusia. Peningkatan sumber daya manusia melalui pendidikan tidak hanya dilakukan dengan mengajarkan ilmu pengetahuan melainkan juga dilakukan melalui pembentukan sikap sosial dan spiritual (Yulianti et al., 2018). Dalam undang-undang Sistem Pendidikan Nasional Nomor 20 Tahun 2003 disebutkan salah satu tujuan pendidikan adalah menjadikan peserta didik yang beriman dan bertakwa kepada Tuhan Yang Maha Esa yang diwujudkan dalam bentuk pendidikan agama Islam bagi sekolah yang memiliki siswa muslim (Habe \& Ahiruddin, 2017; Setiawan, 2017). Pendidikan Pendidikan Agama Islam merupakan salah satu mata pelajaran wajib yang diikuti oleh siswa muslim dalam upaya membina akhlak siswa untuk menjadi manusia yang taat dengan ajaran agama yang dianutnya serta dapat membina 
karakter agar siswa memiliki sikap santun, budi pekerti yang tinggi serta saling menghargai sesama sehingga pembentukan karakter siswa melalui Pendidikan Agama (Shunhaji, 2019; Tambak, 2017; Utomo, 2018). Dalam pendidikan agama islam peserta didik dibimbingan dan diasuh agar dapat memahami apa yang terkandung dalam Islam secara keseluruhan, menghayati makna dan maksud serta tujuannya, dan dapat mengamalkannya (Elihami \& Syahid, 2018; Septiani \& Kejora, 2021).

Pada dasarnya tujuan akhir pendidikan agama Islam itu identik dengan tujuan hidup orang Islam yakni membekali kepribadian peserta didik ke arah yang lebih baik, agar secara spiritual peserta didik mampu bersosialisasi dan beradaptasi dengan lingkungannya (Husaini, 2021; Imelda, 2018; Rohman \& Hairudin, 2018). Untuk memenuhi tujuan pembelajan tersebut maka guru dituntut untuk mampu memberikan pemahaman yang baik mengenai ilmu agama yang didasarkan atas ayat-ayat suci Al-quran. Namun pada proses pelaksanaannya, tujuan pendidikan agama islam belum dapat terpenuhi dengan maksimal. Hal ini dapat dilihat dari hasil belajar siswa yang dicapai setiap melakukan evaluasi hasil belajar belum mencapai nilai KKM yang distandarkan sekolah yaitu 79 untuk Pendidikan Agama Islam. Rendahnya hasil belajar siswa pada pembelajaran Pendidikan Agama Islam cenderung disebabkan oleh kejenuhan dari siswa yang menganggap bahwa pembelajaran Pendidikan Agama Islam selama ini yang diikutinya terasa kurang inovatif, dan kesempatan bagi siswa untuk bereksplorasi melalui praktek Agama masih kurang. Hal ini memang kenyataan demikian karena kurangnya waktu untuk memberikan kesempatan kepada siswa untuk melakukan aplikasi pengetahuan dalam bentuk praktik masih kurang. Faktor lain adalah karena basic (dasar) dari siswa, dimana mayoritas siswa yang belajar di sekolahsekolah umum (SMK) memiliki dasar yang belum maksimal. Akibatnya, ketika siswa dihadapkan pada materi agama khususnya yang berkaitan dengan QS Yunus/10: 40-41 dan QS al Maidah/5: 32 siswa akan mengalami kesulitan pada proses belajarnya.

Salah satu upaya yang dapat dilkukan untuk meningkatkan hasil belajar Agama Islam dan memenuhi tujuan pendidikan agama islam yakni dengan menerapkan model pembelajaran yang tepat. Salah satu model pembelajaran yang sesuai dengan pembelajaran agama islam yakni model pembelajaran discoveri learning. Pembelajaran Discovery Learning merupakan suatu komponen penting dalam pendekatan konstruktivis yang telah memiliki sejarah panjang dalam dunia pendidikan (Setyawati, 2019). Model Discovery Learning merupakan suatu prosedur mengajar yang mementingkan pengajaran perseorangan, manipulasi obyek dan lain-lain, sebelum sampai kepada tahap generalisasi (Rismayani, 2013). Pada kegiatan pembelajaran menggunakan model discovery learning kegiatan pembelajaran difokuskan kepada siswa dan guru hanya bertindak sebagai fasilitator (Junaedi, 2020; Sudirta, 2020). Hal ini dikarenakan pada pembelajaran model pembelajaran discovery learning guru tidak langsung menarik kesimpulan atas kegiatan pembelajaran yang telah dilakukan melainkan memberikan kesempatan kepada siswa untuk menyelidiki, mencari, menemukan sendiri dan memecahkan masalah materi yang dipelajari sehingga siswa dapat mengasimilasi konsep dasar sehingga menambah pengalaman belajar mereka (Annisa \& Sholeha, 2021; Arifudin et al., 2016; Istikomah, 2020).

Melalui prosedur pembelajaran yang sedemikian pembelajaran pendidikan agama islam degan menggunakan model discovery learning diyakini akan dapat meningkatkan hasil belajar siswa. Pernyataan ini juga didasarkan atas penelitian terdahulu yang menyatakan bahwa model pembelajaran discovery learning dapat membangkitkan proses pembelajaran sehingga siswa dapat berkontribusi secara aktif, kritis dan analitis, yang kemudian berdampak pada peningkatan hasil belajar siswa pada mata pelajaran Pendidikan Agama Islam (Annisa \& Sholeha, 2021). Selain dapat meningkatkan hasil belajar siswa model pembelajaran discovery learning juga dapat meningkatkan motivasi belajar peserta didik (Sulfemi \& Yuliana, 2019). Pembelajaran model discovery learning secara signifikan juga dapat meningkatkan hasil belajar siswa (Kristin, 2016). Berdasarkan beberapa penelitian relevan diatas dapat diketahui bahwa penggunaan model pembelajaran discovery learning mampu meningkatkan aktifitas belajar, motivasi belajar, serta hasil belajar siswa. Sehingga tujuan dari penelitian ini yakni untuk mengetahui peningkatan hasil belajar terhadap mata pelajaran Pendidikan Agama Islam setelah diterapkannya model pembelajaran Discovery Learning secara tepat.

\section{METODE}

Penelitian ini merupakan Penelitian Tindakan Kelas yang dilaksanakan dalam beberapa siklus penelitian. Setiap siklus dalam penelitian terdiri atas 4 tahap penelitian yang terdiri dari tahap perencanaan, tahap pelaksanaan tindakan, tahap pengamatan dan tahap refleksi. Tahap pertama yakni tahap perencanaan dilakukan dengan menyusun Rencana Perencanaan Pembelajaran (RPP), materi pokok yang akan diajarkan kepada siswa bersama dengan Indikatornya. Selanjutnya pada tahap kedua yakni tahap pelaksanaan tindakan, dilakukan pelaksanaan pembelajaran sesuai dengan scenario pembelajaran yang telah ditetapkan pada RPP. Tindakan dilakukan untuk penyempurnaan kekurangan 
yang terjadi pada pembelajaran yang telah berlangsung. Tahap ketiga yakni tahap pengamatan. Pada tahap ini dilakukan proses observasi terhadap pelaksanaan tindakan dengan menggunakan lembar observasi yang telah dibuat, dan pada tahap yang terakhir yakni tahap refleksi dilakukan sebagai acuan untuk perbaikan pada siklus berikutnya.

Subjek yang terlibat dalam penelitian ini yakni 20 orang siswa kelas XI SMK Negeri 5 Kota Ternate tahun pelajaran 2017/2018. Kelas tersebut dijadikan sebagai subjek penelitian karena kualitas pembelajaran dan hasil belajar Agama Islam masih di bawah KKM . Pengumpulan data dalam penelitian ini dilakukan dengan menggunakan Instrumen Penelitian yang terdiri dari: Instrumen Penilaian Hasil Belajar Pendidikan Agama Islam (dengan materi QS Yunus/10:40-41 dan QS al Maidah /5 : 32), Instrumen Wawancara, Instrumen Pengamatan, dan Instrumen Isian oleh Objek atau Siswa. Data yang terkumpul dianalisis secara deskriptif kuantitatif.

\section{HASIL DAN PEMBAHASAN}

Berdasarkan penelitian yang telah dilakukan dengan menerapkan model pembelajaran Discovery Learning pada siswa kelas XI semester satu SMK Negeri 5 Kota Ternate tahun pelajaran 2017/2018 maka didapatkan hasil bahwa pada siklus I terdapat peningkatan hasil belajar Pendidikan Agama Islam siswa , dimana pada siklus I sebanayk 9 orang telah tuntas pada mata pelajaran pendidikan agama islam dengan persentase peningkatan ketuntasan yakni 35\% dari prasiklus. Dari paparan hasil siklus I dapat diketahui bahwa telah terjadi peningkatan rata-rata nilai dari pra siklus. Hasil capaian pada siklus I dengan nilai rata-rata kelas adalah 79 sedangkan ketuntasan belajar mencapai $75 \%$. Hanya saja hasil pada siklus I masih belum optimal sehingga penelitian dilanjutkan pada siklus II. Pada siklus II diporoleh jumlah nilai rata-rata sebesar 83 dan ketuntasan belajar mencapai 100\%. Peningkatan hasil yang dicapai siswa pada siklus II karena dilakukan refleksi secara maksimal melalui penerapan model pembelajaran Discovery Learning dalam pembelajaran. Pada siklus II Siswa merasa terbina untuk berupaya meningkatkan hasil belajar dan mencapai ketuntasan secara maksimal terhadap Pendidikan Agama Islam dengan materi .Q.S. Yunus/10 : 40-41 dan Q.S. al-Maidah/5: 32/ Keseluruhan hasil yang telah dicapai dalam penelitian tindakan kelas ini dapat disajikan dalam tabel dibawah ini.

Tabel 1. Rekapitulasi Hasil Penelitian Tindakan Kelas

\begin{tabular}{ccccc}
\hline \multirow{2}{*}{ Kreteria } & \multicolumn{3}{c}{ Jenis Tindakan } & \multirow{2}{*}{ Ket. } \\
\cline { 2 - 4 } & Pre test/Prasiklus & S.I & S.II & Meningkat \\
Jumlah Nilai & 1394 & 1573 & 1683 & Meningkat \\
Rata-rata Nilai & 70 & 79 & 83 & Meningkat \\
Ketuntasan Belajar & $40 \%$ & $75 \%$ & $100 \%$ & Menurun \\
Siswa Yang Belum Tuntas & $60 \%$ & $25 \%$ & 0 & .
\end{tabular}

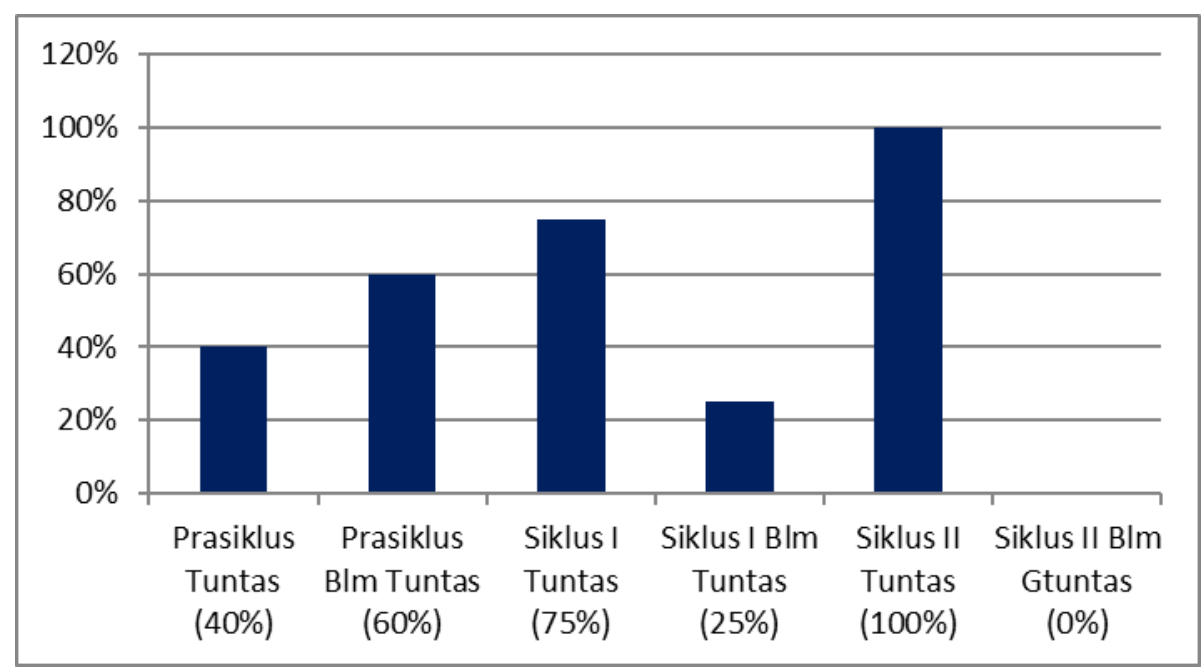

Gambar 2. Grafik Keseluruhan Hasil Penelitian Tindakan Kelas

Berdasarkan tabel 1 dapat diketahui bahwa terdapat peningkatan hasil belajar Pendidikan Agama Islam di setiap siklusnya, hal ini menunjukkan bahwa penggunaan model pembelajaran discovery learning efektif digunakan untuk meningkatkan hasil belajar siswa. Temuan pada penelitian ini sejalan dengan 
temuan peneliti sebelumnya yang menyatakan bahwa yang menyatakan bahwa model pembelajaran discovery learning dapat membangkitkan proses pembelajaran sehingga siswa dapat berkontribusi secara aktif, kritis dan analitis, yang kemudian berdampak pada peningkatan hasil belajar siswa pada mata pelajaran Pendidikan Agama Islam (Annisa \& Sholeha, 2021). Selain dapat meningkatkan hasil belajar siswa model pembelajaran discovery learning juga dapat meningkatkan motivasi belajar peserta didik (Sulfemi \& Yuliana, 2019). Pembelajaran model discovery learning secara signifikan juga dapat meningkatkan hasil belajar siswa (Kristin, 2016).

Adanya peningkatan hasil belajar siswa setlah diterapkannya model discovery learning disebabkan karena, model ini meletakkan siswa sebagai fokus utama dalam kegiatan pembelajaran, sehingga guru hanya sebagai fasilator dan pengantar materi (Irdam \& Irawati, 2019; Rudyanto, 2016). Kegiatan pembelajaran dengan menggunakan model Discovery Learning cenderung lebih kompleks, banyak menuntut aktivitas berpikir dan bahkan tidak jarang pula menuntut sejumlah aktivitas fisik (Rosinah, 2020). Terdapat beberapa bentuk kegiatan yang dapat dilaksanakan melalui model Discovery Learning, seperti bertanya jawab, berdiskusi, melakukan pengamatan, mengadakan percobaan mewawancarai narasumber melakukan latihan-latihan, bersimulasi, mengadakan permainan, mengerjakan tugas-tugas, mengadakan penelitian sederhana, memecahkan masalah, dan sebagainya (Junaedi, 2020). Pada kegiatan pembelajaran dengan model Discovery Learning guru memberikan kebebasan siswa untuk menemukan dan merangkai sendiri ilmu pengetahuannya, sehingga kegiatan pembelajaran dapat lebih bermakna bagi siswa.

\section{SIMPULAN}

Berdasarkan penelitian yang telah dilakukan, dapat disimpulkan bahwa hasil belajar pendidikan agama Islam materi Q.S Yunus/10:40-41 dan QS Al Maidah /5:32 secara signifikan dapat ditingkatkan dengan model pembelajaran discovery learning pada siswa kelas XI semester satu SMK Negeri 5 Kota Ternate tahun pelajaran 2017/2018. Berdasarkant hasil penelitian dapat diberikan saran kepada guru Pendidikan Asgama Islam di SMK Negeri 5 Kota Ternate agar lebih selektif dalam menggunakan metoda atau model pembelajaran dalam melaksanakan pembelajaran. Sebab metoda atau model mengajar yang kurang tepat memberi dampak yang kurang baik terhadap hasil belajar siswa dan siswa merasa kurang nyaman dalam mengikuti pembelajaran jika metoda atau model pembelajaran yang digunakan guru kurang tepat.

\section{DAFTAR RUJUKAN}

Annisa, \& Sholeha, D. (2021). Upaya Peningkatan Hasil Belajar Siswa Melalui Metode Pembelajaran Discovery Learning. Indonesian Journal of Teacher Education, 2(1), 6. https://journal.publicationcenter.com/index.php/ijte/ article/view/245.

Arifudin, M., Wilujeng, H., \& Utomo, R. B. (2016). Pengaruh Metode Discovery Learning Pada Materi Trigonometri Terhadap Kemampuan Penalaran Adaptif Siswa Sma. Kalamatika Jurnal Pendidikan Matematika, 1(2), 129. https://doi.org/10.22236/kalamatika.vol1no2.2016pp129-140.

Elihami, E., \& Syahid, A. (2018). Penerapan Pembelajaran Pendidikan Agama Islam Dalam Membentuk Karakter Pribadi Yang Islami. Edumaspul - Jurnal Pendidikan, 2(1), 79-96. https://doi.org/10.33487/edumaspul.v2i1.17.

Habe, H., \& Ahiruddin. (2017). Sistem pendidikan nasional. Jurnal Ekonomi, Keuangan, Dan Sains, 2(1). https://doi.org/10.24967/ekombis.v2i1.48.

Husaini, H. (2021). Hakikat Tujuan Pendidikan Agama Islam Dalam Berbagai Perspektif. Jurnal Kajian Perbatasan Antarnegara, 4(1), 114-126. http://journal.iaisambas.ac.id/index.php/CrossBorder/article/view/525/420.

Imelda, A. (2018). Implementasi Pendidikan Nilai Dalam Pendidikan Agama Islam. Al-Tadzkiyyah: Jurnal Pendidikan Islam, 8(2), 227. https://doi.org/10.24042/atjpi.v8i2.2128.

Irdam, I., \& Irawati, S. (2019). Analisis Model Pembelajaran Discovery Learning Dalam Meningkatkan Hasil Belajar Ipa-Biologi. Talenta Conference Series: Science and Technology (ST), 2(2). https://doi.org/10.32734/st.v2i2.532.

Istikomah, D. D. (2020). Penerapan Model Problem Based Learning dengan Media Daring Zoom Meet dalam Meningkatkan Keaktifan Siswa dan Hasil Belajar Siswa Pada Pembelajaran Gangguan Pada Organ Peredaran Darah Manusia di kelas 5 tema 4 SDN Pengkol 2 Sragen Tahun Pelajaran 2020/ 2021. JP3 (Jurnal Pendidikan Dan Profesi Pendidik), 6(1). https://doi.org/10.26877/jp3.v6i1.7337.

Junaedi, D. (2020). Penerapan Model Pembelajaran Discovery Untuk Meningkatkan Hasil Belajar Siswa Pada Pembelajaran Pendidikan Kewarganegaraan. Jurnal Educatio, 6(1), 55-60. 
https://doi.org/10. 31949/educatio.v6i1.209 P-ISSN.

Kristin, F. (2016). Analisis Model Pembelajaran Discovery Learning Dalam Meningkatkan Hasil Belajar Siswa SD. Jurnal Pendidikan Dasar PerKhasa, 2(1). https: //doi.org/10.31932/jpdp.v2i1.25.

Rismayani, N. L. (2013). Penerapan Model Pembelajaran Discovery Learning Untuk Meningkatkan Hasil Belajar PKN Siswa. Jurnal Pendidikan Kewarganegaraan Undiksha, 1(2). https://doi.org/10.23887/jpku.v1i2.405.

Rohman, M., \& Hairudin, H. (2018). Konsep Tujuan Pendidikan Islam Perspektif Nilai-nilai Sosial-kultural. Al-Tadzkiyyah: Jurnal Pendidikan Islam, 9(1), 21. https://doi.org/10.24042/atjpi.v9i1.2603.

Rosinah, R. (2020). Penerapan Model Problem Based Instruction (PBI) dengan Media Kartu Pintar untuk Meningkatkan Kualitas Pembelajaran IPA pada Peserta Didik Kelas IV SDN 211/IX Mendalo Darat. Jurnal Ilmiah Dikdaya, 10(2), 190. https: //doi.org/10.33087/dikdaya.v10i2.175.

Rudyanto, H. E. (2016). Model Discovery Learning Dengan Pendekatan Saintifik Bermuatan Karakter Untuk Meningkatkan Kemampuan Berpikir Kreatif. Premiere Educandum: Jurnal Pendidikan Dasar Dan Pembelajaran, 4(01). https://doi.org/10.25273/pe.v4i01.305.

Septiani, A., \& Kejora, M. T. B. (2021). Tingkat Aktivitas Belajar Siswa pada Pembelajaran Online Pendidikan Agama Islam di Masa Pandemi Covid-19. Jurnal Ilmu Pendidikan, 3(5), 2594-2606. https://doi.org/10.31004 /edukatif.v3i5.914.

Setiawan, D. (2017). Pendekatan Saintifik Dan Penilaian Autentik Untuk Meningkatkan Mutu Pembelajaran Pendidikan Agama Islam. Journal of Basic Education, 1(2), 34-46. https: //doi.org/10.24269/ajbe.v1i2.683.

Setyawati, I. (2019). Upaya Meningkatkan Proses Pembelajaran dan Hasil Belajar IPA Melalui Model Discovery Learning. Jurnal Kajian Teori Dan Praktik Kependidikan, 3(1), 12-23. http://journal2.um.ac.id/index.php/jktpk/ article/view/4437.

Shunhaji, A. (2019). Agama Dalam Pendidikan Agama Islam Di Sekolah Dasar. Jurnal Pendidikan Islam, 1(1), 1-21. https://doi.org/10.36671/andragogi. v1i1.46.

Sudirta, I. W. (2020). Meningkatkan Hasil Pembelajaran Bahasa Indonesia Materi Teks Cerita Novel Melalui Penerapan Model Pembelajaran Discovery Learning. Journal of Education Action Research, 5(2), 179-186. https://doi.org/10.23887/mpi.v1i2.30194.

Sulfemi, W. B., \& Yuliana, D. (2019). Penerapan Model Pembelajaran Discovery Learning Meningkatkan Motivasi Dan Hasil Belajar Pendidikan Kewarganegaraan. Jurnal Rontal Keilmuan PKn, 5(1), 1730. https://doi.org/10.29100/jr.v5i1.1021.

Tambak, S. (2017). Metode Cooperative Learning dalam Pembelajaran Pendidikan Agama Islam. Jurnal AlHikmah, 14(1). https://doi.org/10.25299/ al-hikmah:jaip.2017.vol14(1).1526.

Utomo, K. B. (2018). Strategi Dan Metode Pembelajaran Pendidikan Agama Islam Mi. Jurnal Program Studi PGMI, 5(2), 145-156. http://jurnal.stitnualhikmah.ac.id/index.php/modeling/article/view/331.

Yulianti, H., Iwan, C. D., \& Millah, S. (2018). Penerapan Metode Giving Question and Getting Answer untuk Meningkatkan Hasil Belajar Peserta Didik pada Mata Pelajaran Pendidikan Agama Islam. Jurnal Penelitian Pendidikan Islam, 6(1). https://doi.org/https://doi.org/10.36667/jppi.v6i2.297. 